\title{
research provocations
}

\section{Expert knowledge and policymaking: a multi-disciplinary research agenda}

\author{
Johan Christensen, j.christensen@fgga.leidenuniv.nl \\ Leiden University, Netherlands
}

\begin{abstract}
The role of experts and expert knowledge in policymaking has attracted growing public and academic attention. Scholarship on the topic has, however, remained deeply fragmented. It is discussed in separate silos of the literature - such as evidence-based policymaking, epistemic communities, and ideas and politics - and this has hindered sustained empirical study. This article argues that to stimulate more systematic research on the role that experts play in policymaking and develop a theoretical understanding of it, we need to foster dialogue across these literatures. To facilitate this, the article critically reviews how the role of expert knowledge in policymaking is conceptualised and explained in existing literatures, and offers suggestions about how to create common ground for future research by reframing research around the question of the influence of experts, and examining more closely the administrative underpinnings of expert influence.
\end{abstract}

Key words expert knowledge $\cdot$ evidence-based policymaking $\cdot$ EBP $\cdot$ expertise $\cdot$ research utilisation $\bullet$ knowledge brokering $\cdot$ evidence mobilisation $\bullet$ epistemic communities

To cite this article: Christensen, J. (2020) Expert knowledge and policymaking: a multi-disciplinary research agenda, Policy \& Politics, vol xx, no xx, 1-17, DOI: 10.1332/030557320X15898190680037

\section{Introduction}

The place of experts in politics and policymaking has attracted increasing attention in recent decades, both in public and academic debate. On the one hand, scholars highlight the growing role of expertise in policymaking: decision-makers are increasingly reliant on advanced knowledge to understand and address complex societal problems (Haas, 1992), face growing expectations that policies should be based on the best available evidence about the effectiveness of policy interventions (Davies et al, 2000; Jennings and Hall, 2012; Head, 2015), and are influenced by powerful expert professionals such as economists (Fourcade, 2006; Chwieroth, 2010). On the other hand, scholars point to an increasing contestation and politicisation of expert knowledge by decision-makers (Weingart, 1999). Not only is expert knowledge often used as political ammunition or as a tactical tool rather than for genuine problemsolving (Boswell, 2008), it is also regularly rejected or delegitimised by politicians, especially during the current wave of populist politics (Nichols, 2017). 
Yet, despite the growing interest in the role of expert knowledge in policymaking, scholarship has remained remarkably fragmented. Different sub-disciplines of political science (including public policy) and sociology have engaged in parallel monologues about the role of expertise in policymaking. The topic is discussed under various headings, including 'evidence-based policymaking', 'knowledge utilisation', 'ideas', 'epistemic communities' and 'professions', and in 'science and technology studies' (STS). These literatures propose distinct concepts and theoretical arguments for capturing and explaining the policy role of expert knowledge. These bodies of scholarship have to a large extent developed separately and speak to each other only casually, however.

The fragmented state of the literature is bewildering for anyone interested in understanding the influence of expert knowledge in policymaking. It has also been a barrier to theoretical development and empirical analysis. While similar concepts and arguments have multiplied across literatures, there has been little discussion of the connections between the various concepts and arguments or critical examination of their relative strengths and weaknesses. Many existing explanatory arguments have important weaknesses and blind spots, and arguments trumpeted as theoretical innovations in one literature are long-established assumptions in other literatures. The lack of discussion across literatures has also hindered more systematic empirical investigation. Central concepts proposed for understanding the policy role of experts have received limited critical scrutiny. As a result, scholarship is rife with concepts that are difficult to operationalise and study empirically, such as 'epistemic communities' or different types of 'knowledge utilisation'.

The goal of this article is to stimulate the academic debate on expertise and policymaking by looking across literatures. The article first critically assesses how different bodies of scholarship have addressed two central problems: how to capture conceptually the role of experts or expert knowledge in policymaking, and how to explain the varying role of expert knowledge in policymaking. The article points to differences and similarities in how these questions are answered across literatures and highlights weaknesses of the concepts and theoretical arguments proposed by each approach.

Building on this critique, the article then presents two novel suggestions about how future research on expertise and policymaking can overcome the problems of the currently fragmented field. These proposals cut across existing divides between literatures. First, the article proposes to reframe the discussion about the policy role and utilisation of expert knowledge as a question of influence, that is, to focus research squarely on the influence of experts and their knowledge over public policy. This entails a 'normalisation' of research on expertise and policymaking, seeing experts as one type of actor among others providing input in the political system rather than granting them a special status as providers of neutral and apolitical evidence. Second, it argues that explanatory arguments need to pay greater attention to how the organisation of expert knowledge within public administrations conditions expert influence. The article sketches a theoretical argument about the factors that may affect the position of experts in government bureaucracies and about how the position of experts in these bodies may shape decision-making.

By bridging a broad range of currently separate literatures, the article makes a distinct contribution to debates about expertise and policymaking. Existing review articles have been limited to specific literatures or types of expertise, such as ideas 
and public policy (Campbell, 2002), expertise in policy sub-systems (Weible, 2008), epistemic communities (Cross, 2013; Dunlop, 2013), economic expertise (Hirschman and Berman, 2014), knowledge utilisation (Daviter, 2015) and evidence-informed policymaking (Head, 2015), or do not capture recent theoretical developments (Radaelli, 1995). By creating a critical dialogue between these literatures and outlining a cross-cutting research agenda, the article seeks to stimulate conceptual and theoretical discussion and more sustained empirical research on the policy influence of experts.

To be sure, the broad scope of the article comes with challenges. One issue is the definition of 'expert knowledge'. While the article takes as its starting point common understandings of expertise as scientific, academic or professional knowledge, it also includes work that takes a wider view of expertise. (Table 1 provides an overview of the definitions of expert knowledge in the different literatures.) Another issue is which literatures to include. The article concentrates on currently active literatures in different sub-disciplines of political sciences and sociology that deal directly and centrally with the role of expert knowledge in public policymaking. ${ }^{1}$ The article thus focuses on concepts and arguments frequently used by scholars today.

The discussion of existing literature also aims to critically examine a selection of central concepts and arguments from each literature. It is not a systematic literature review based on systematic database searches and selection procedures, and it does not seek to present a comprehensive overview of work in each field. Rather, the selection of sources is based on the researcher's and other researchers' assessment of what constitutes central contributions. More specifically, the article has used existing review articles of the different literatures to identify important contributions and arguments. Whether this selection covers the most relevant work or should have included other sources is of course up for discussion, and some scholars may feel that the reading of a specific literature is too narrow or biased. These are the necessary limits of this kind of exercise. The article's sometimes-sweeping characterisations and critiques of existing work are, however, precisely meant to provoke reflection and debate on how to theorise and study the policy influence of experts and expertise.

Over the next pages, the article compares and critically discusses how the literatures on evidence-based policymaking, knowledge utilisation, ideas, professions, epistemic communities and STS conceptualise and explain the role of expert knowledge in policymaking. It then presents and discusses two promising avenues for future research. The concluding section considers some potential objections to the argument of the article.

\section{Existing perspectives on expert knowledge and policymaking}

The topic of expertise and policymaking is discussed within various literatures in political science and sociology. Table 1 provides a quick overview of these literatures, summarising how the object of study, notion of expert knowledge/evidence, and arguments about determinants and effects of expert knowledge vary across the literatures.

\section{Capturing the role of expert knowledge in policymaking}

The first main challenge facing scholars of expertise and policymaking is how to capture conceptually the role of expert knowledge in public policymaking. Should the attention be focused on the knowledge or expert idea itself, on the expert, or rather 


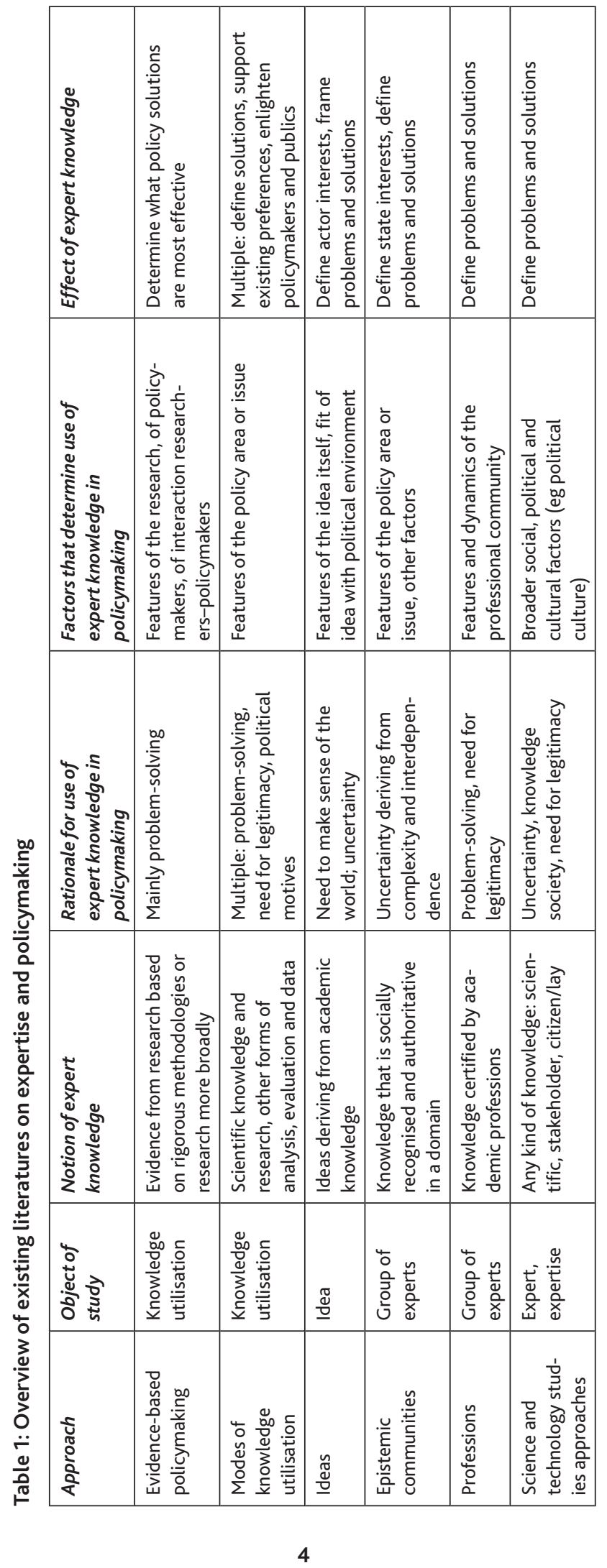


on the groups that produce and spread expert knowledge? Should the impact of expert knowledge on policymaking be examined as a question of evidence uptake, knowledge utilisation or something else? Different literatures provide diverging answers to these questions.

In the field of public policy, there is a long-standing tradition for research on the utilisation of information, research or knowledge in policymaking (Weiss, 1979; Sabatier, 1987; Oh and Rich, 1996; Landry et al, 2003; Weible, 2008). This work argues that information derived from research and analysis can be an important ingredient of policymaking, which makes it important to understand how it enters the policy process. One currently prominent strand of literature that has flowed out of this work is the research on evidence-based policymaking (Head, 2015). This literature is centrally concerned with understanding the use or 'uptake' of evidence in policy design, with evidence usually referring to results of some sort of formal and systematic investigation (Davies et al, 2000: 3; Oliver et al, 2014). Yet, a problem with notions of 'evidence uptake' and similar is that they are normatively charged. They rest on the assumption that research evidence is neutral and apolitical and will contribute to more rational policymaking (see Cairney et al, 2016; Newman, 2017).

A second and related strand of literature challenges the idea that research utilisation mainly takes the form of genuine problem-solving. It instead distinguishes several alternative models for describing the different ways in which scientific knowledge is used in the policy process, including a strategic model, in which knowledge is used as political ammunition to support predetermined policy positions, and a symbolic model, in which knowledge is used to gain legitimacy vis-a-vis other actors (Weiss, 1979; Boswell, 2008; Schrefler, 2010; Rimkutè and Haverland, 2015). ${ }^{2}$ Yet, the notion of different 'modes of knowledge utilisation' has some significant problems. First, the types of knowledge use are difficult to distinguish empirically. Central contributions either do not attempt to operationalise the modes of knowledge use (for example, Radaelli, 1999) or run into trouble when trying to translate the typology into empirically identifiable measures (for example, Boswell, 2008: 474-6; Schrefler, 2010: 318-19). Second, the typology of knowledge utilisation obscures the distinction between the intentions behind drawing on knowledge and the actual impact of the knowledge. For instance, an expert appointed to a government function for symbolic reasons may in the end have considerable policy influence.

An alternative approach is to think about the policy role of expert knowledge through the lens of ideas. In the 'ideas and politics' literature in political science, the main object of study is the expert idea itself rather than knowledge utilisation or expert actors (Hirschman and Berman, 2014). This literature investigates how ideas deriving from academia and research - both broader problem definitions and concrete ideas about policy solutions - shape public policies (Hall, 1989; 1993; Campbell, 2002; Béland and Cox, 2010). A problem with the focus on ideas, however, is that it draws the attention away from the actors that produce, carry and promote these ideas (Campbell, 2002: 29-30).

By contrast, work in STS on expertise and policymaking has been centrally concerned with the role of the expert providing advice to decision-makers (see Grundmann, 2017). ${ }^{3}$ A core argument is that experts are mediators or brokers between the production of knowledge and its application to policy. This activity is not neutral or value-free but rather socially and politically embedded: experts provide advice to decision-makers based not only on scientific evidence but also on social and political 
judgement (Jasanoff, 2005a). For instance, Pielke distinguishes various roles experts can adopt when advising decision-makers, including pure scientist, science arbiter, issue advocate and honest broker (Pielke, 2007). How the different expert roles can be operationalised and systematically studied is seldom specified in this literature, however.

Other literatures seek to capture the role of expertise in policymaking by focusing on the groups of experts that produce and carry knowledge. One is the sociological work on professions (Wilensky, 1964; Larson, 1979; Abbott, 1988; Fourcade, 2009). This work argues that expert professions may have considerable power in public policymaking, deriving from their special knowledge and exclusive character. Members of a profession are bound together by shared knowledge, skills and worldviews derived from a common educational background and are thus inaccessible to those without such training. Since professionals working in policymaking organisations identify with and take behavioural cues from their professional community, professions are important vehicles for the spread of expert knowledge to policymaking.

Another literature that focuses on groups of experts is the work on epistemic communities in international relations (Haas, 1992; Adler and Haas, 1992; Cross, 2013). ${ }^{4}$ It highlights the policymaking role of networks of experts 'with recognised expertise and competence in a particular domain and an authoritative claim to policyrelevant knowledge within that domain or issue-area' (Haas, 1992: 3). Epistemic communities not only have shared beliefs about cause-and-effect relationships and shared criteria for validating knowledge but also have shared normative beliefs and a common policy enterprise. This concept differs subtly from that of a profession: while a common education is what unifies and defines a profession, an epistemic community may include professionals from various disciplines. And whereas an epistemic community is delimited by shared normative ideas, members of a profession will not necessarily have the same normative ideas (Haas, 1992: 19).

A major weakness of the epistemic community concept is that the boundaries of the community are notoriously difficult to determine empirically, since it requires detailed evidence on beliefs that is rarely available. In practice, this has led to considerable conceptual slippage, with many groups of experts being labelled as epistemic communities without evidence that they satisfy Haas's criteria (Dunlop, 2013). In comparison, the criterion used by the professional literature to define the boundaries of expert communities - educational background - is both theoretically justified and clear and empirically traceable. The disadvantage, however, is that it excludes actors who do not have the 'right' education but who believe in and advocate a particular policy idea. The concept of a profession is therefore less suited to capture the influence of coalitions spanning different disciplines and types of professional knowledge than the notion of an epistemic community.

\section{Explaining the role of expert knowledge in policymaking}

The second main challenge facing scholars is how to explain the role of experts and expert knowledge in policymaking. Regarding the basic reasons for drawing on expert knowledge there is considerable agreement across literatures. Most fundamentally, decision-makers need expertise to make sense of the policy issues they face and to design solutions to these problems. The ideational and epistemic communities literatures also go further by arguing that actors need knowledge and ideas to define their interests (Haas, 1992; Béland and Cox, 2010). Moreover, the need for expert 
knowledge has grown with the increasing specialisation and complexity of society, which confront decision-makers with growing uncertainty (Haas, 1992). Different literatures also highlight that the demand for expert knowledge derives not only from a need to solve policy problems but also from the desire to enhance the legitimacy of policymaking by making it appear rational and objective (Weiss, 1979; Markoff and Montecinos, 1993; Fourcade, 2006; Boswell, 2008).

Existing literatures present strikingly different arguments about the conditions under which expert knowledge is used in policymaking, however. The evidence-based policymaking literature highlights several determinants of evidence utilisation, including characteristics of the research itself, for example, its clarity, relevance and quality; features of the policymaker, for example, her research skills and research awareness; and the character of the relationship and communication between researchers and policymakers (see Oliver et al, 2014; Head, 2015). One problem with these arguments is that they have a decidedly rationalist flavour (see Parkhurst, 2017:23): Evidence utilisation is attributed to researchers' supply of relevant evidence, policymakers' demand for evidence, and efficient transmission of evidence between the two. Knowledge utilisation is thereby reduced to a sort of engineering problem. Moreover, this work often takes an atheoretical approach to explaining evidence use, presenting laundry lists of factors that facilitate or hinder evidence use rather than theoretically grounded accounts. Recent work has paid greater attention to the politics of evidence-based policymaking, drawing on insights from policy theory (Cairney et al, 2016; Parkhurst 2017). Yet the proposed theoretical arguments offer only a rudimentary notion of the politics of expertise compared to other literatures. Notably, they neglect the role of bureaucracies in shaping the use of evidence in policymaking (Christensen, 2018).

The ideational literature often points to features of ideas and their relation to the political environment to explain why some expert ideas are adopted while others are not.This includes features of ideas such as their flexibility or ambiguity (Hall, 1989:366), clarity or simplicity (see Campbell, 2002: 29) or valence, that is, 'the emotional quality of an idea that makes it more or less attractive' (Cox and Béland, 2013: 307), and the 'fit' between the idea and the environment, that is, how well ideas match existing political-economic problems, administrative practices and political interests and discourse (Hall, 1989). Arguments that link the success of an idea to features of the idea are, however, questionable theoretically and hard to prove empirically. Some arguments are equally plausible when turned on their head: while an ambiguous idea may be acceptable to a broader range of actors, a clear idea may be more convincing. In other cases, the proposed explanatory factor lies dangerously close to the outcome itself. An example is the argument about valence, which links the success of ideas to their attractiveness. Arguments that tie the influence of ideas to their fit can suffer from the same problem, since it is often difficult to determine the fit of an idea independent of its success (but see Smith, 2013).

Recently, ideational scholars have also pointed to explanatory factors at the system level. Campbell and Pedersen (2014) argue that the adoption of particular expert ideas is conditioned by national 'knowledge regimes', that is, by the character of the organisations producing policy-relevant knowledge and the institutions regulating them. Work in STS similarly points to political and cultural features at the societal level as important for understanding knowledge use. A prominent example is Sheila Jasanoff's argument that the different patterns of knowledge use in American and 
European policy in the field of life sciences reflected different political-cultural traditions regarding public knowledge, what she terms 'civic epistemologies' (Jasanoff, 2005b). A problem with these arguments is that they are often hard to verify empirically. The chain connecting broader features of politics and society (for example, a consensual political culture) to how specific organisations and actors use expert knowledge is long and difficult to trace empirically.

The knowledge utilisation literature (and to a lesser extent also the epistemic communities literature) primarily points to features of the policy issue or area to explain how knowledge is used.This includes the degree of uncertainty surrounding an issue, political salience or the degree of contestation (Radaelli, 1999; Boswell, 2008; Schrefler, 2010). For instance, when political salience is high, knowledge will be used in more strategic ways. These arguments are rather generic, however, and leave a lot of interesting variation unexplained. For instance, they are not able to account for why organisations of the same kind that operate in the same policy area use knowledge differently.

By contrast, the sociological literature on professions highlights how the internal dynamics of professions shape the role of experts in policymaking. These dynamics include the mechanisms by which professions reproduce themselves and the mechanisms through which ideas change and spread within professional communities (DiMaggio and Powell, 1983; Fourcade, 2006; Chwieroth, 2010). In this regard the professional literature offers a more sophisticated account than the epistemic communities literature, which says surprisingly little about the internal dynamics of expert communities and how such dynamics may condition the policy role of experts (Verdun, 1999; Dunlop, 2013; Cross, 2013). However, the emphasis on professional training and dynamics as determinants of behaviour and influence tends to overshadow other important explanatory factors. For instance, the professional literature pays too little attention to how professional beliefs are reshaped or suppressed within policymaking organisations that place competing demands on professionals.

Finally, various literatures suggest that institutional and organisational factors matter for the policy role of expert knowledge. Some ideational scholars point to the institutional preconditions for the influence of ideas, such as how different institutional structures filter the access of expert ideas (Weir and Skocpol, 1985; Smith, 2013) or how ideas gain impact by becoming institutionally embedded (Campbell, 2002:30-1; Béland and Cox, 2010:9). Haas similarly highlights that the power of an epistemic community may be cemented through the elevation of its members into key bureaucratic positions (Haas, 1992: 4). Moreover, some studies of professions argue that experts may use strategic bureaucratic positions to exert influence over public policies (Babb, 2004; Chwieroth, 2010; Christensen, 2017).Yet exactly how features and dynamics of administrative institutions condition expert influence is curiously undertheorised and understudied in current literature. We return to this point later.

\section{Directions for future research}

The discussion of the currently fragmented scholarship on expert knowledge and policymaking has revealed important differences in how the role of expert knowledge in policymaking is conceptualised and explained. It has also highlighted the difficulties in empirically identifying key concepts and the important weaknesses and blind spots of existing explanatory arguments. This section offers two novel suggestions about 
how future scholarship can confront these issues. These suggestions cut across existing literatures and seek to establish a common ground for systematic empirical analyses of the role of expert knowledge in policymaking - whether based on qualitative or quantitative data and whether relying on case studies, comparative analyses or large-n designs. This kind of cumulative research effort is crucial for expanding our understanding of how the role and impact of expert knowledge varies across countries, organisations and policy areas, and of the factors and mechanisms that explain the influence of expertise.

\section{Expert influence}

As argued earlier, systematic research on the policy impact of expert knowledge has been held back by two conceptual problems: should it be studied as a question of evidence uptake, knowledge utilisation or something else, and should it focus on the expertise/expert idea or on the actors that carry expertise? A concrete suggestion for overcoming these problems is to reframe the issue as a question of expert influence, that is, to focus research squarely on the influence of experts and their knowledge over public policy. Influence is one of the most central issues in the study of decisionmaking (March, 1955) and can be defined as 'an actor's ability to shape a decision in line with her preferences' (Dür, 2008: 561). This definition involves three basic elements: (a) an actor, (b) the preferences of the actor regarding a specific policy, and (c) the policy decision that the actor seeks to influence. Applied to expertise and policymaking, it means focusing the analytical attention on the ability of expert actors to shape policy decisions in line with their knowledge-based preferences. Reframing research around the question of expert influence offers several advantages.

First, focusing on expert influence entails a 'normalisation' of scholarship on expertise and policymaking, bringing it into line with literatures that study the influence of other types of actors in public policymaking, such as interest groups and political parties (for example, Burstein and Linton, 2002; Chalmers, 2011). It implies seeing experts as one type of actor that provides input in the political system and competes with other actors for influence, rather than granting experts a special status as providers of neutral and apolitical evidence. In other words, an influence framing steers clear of the normative assumption that experts and expertise ought to play a greater role in policymaking, which underpins much of the work on evidence-based policymaking.

Second, analysing expert influence helps bridge the divide between those literatures that centre on the expert knowledge/idea itself and those that focus on the actors carrying expert knowledge. An influence framework is compatible with both since it includes both a notion of actors and a notion of their substantive policy preferences. For instance, from an ideational perspective, 'preferences' correspond to specific policy ideas and 'actors' are the people who promote these ideas. Applied to the professional and epistemic communities' perspectives, the actors are the members of professions or epistemic communities and the preferences are their shared policy views deriving from expert knowledge. In other words, analysing influence is consistent with different existing approaches and thus offers common ground for future research.

Third, expert influence is more amenable to operationalisation and systematic empirical study than existing concepts such as types of knowledge utilisation. While there are inherent challenges in examining influence, political scientists already 
have analytical tools for doing so. Scholars dealing with the analogous problem of how to determine the policy influence of interest groups distinguish three main methodological approaches to gauging influence (Dür, 2008), which are also readily applicable in studies of expert influence.

The first methodological approach is process-tracing, which entails tracing the process from the preferences of an actor to the final policy decision. Applied to expert influence, this involves empirically tracing the following steps in the influence process: (a) the initial preferences of experts, (b) the access of experts to decisionmakers, (c) the attempts of experts to advocate these preferences to decision-makers, (d) decision-makers' responses to these influence attempts, and (e) the degree to which the preferences of experts are reflected in the final policy decision (see Dür, 2008: 562). Empirical evidence on each step can be gathered through analysis of policy documents and semi-structured interviews with experts, decision-makers and other parties involved in the policy process. This approach is feasible in small-n studies of expert influence. For instance, a recent comparative study of the influence of economists on tax reform applied this kind of methodology, using interviews and documents to trace the initial tax policy preferences of economists, economists' position within government bureaucracies, their efforts to advocate their policy preferences to politicians, politicians' acceptance or rejection of these policy solutions, and the correspondence between the final reform and economists' initial preferences (Christensen, 2017). The major limit of process-tracing is that it can only be applied a handful of cases at a time, which restricts our ability to draw more general conclusions about expert influence. If we want to conduct large-n studies of expert influence, other approaches are needed.

A second possible approach to tracing expert influence is the attributed influence method (see March, 1955; Dür, 2008:565). Rather than tracing the influence process, this method focuses on measuring perceptions of the influence of a specific actor. This includes the actor's own assessment of how much influence she had and the perceptions of other involved actors and informed observers. Applied to expertise and policymaking, it involves asking experts, decision-makers or other involved parties how much influence a specific group of experts had on policy, which can be done through surveys. For instance, some survey-based studies ask government agency officials to assess the influence of university research or other types of evidence on agency decisions (Landry et al, 2003; Jennings and Hall, 2012). One problem with this approach is that it relies on reported perceptions of influence rather than actual influence. Survey responses of this kind are subject to well-known biases such as social desirability bias. Furthermore, this approach is more appropriate for studying expert influence on policymaking in general than for examining influence on specific policy decisions. Usually only a small group of individuals has first-hand knowledge about the influence of expert actors on a specific decision. The views of a broader group of observers who have only second-hand knowledge will not add much to our understanding of the actor's influence on the decision and may even distort the measure of influence.

A third approach to measuring expert influence is to examine the preference attainment of expert actors, that is, to assess the degree to which final policy decisions match initial expert preferences (see Dür, 2008:566). The basic assumption is that the closer a final policy decision comes to the initial preferences of experts, the greater the degree of expert influence. Assessing preference attainment is one important element 
in the process-tracing approach discussed earlier. Preference attainment, however, may also be examined quantitatively across a large number of cases. For instance, scholars could take a large number of reports from expert advisory bodies and investigate the degree to which the recommendations presented in the reports are reflected in policy decisions. However, there are major methodological challenges involved. Not only would scholars need to identify the relevant policy decision or lack of a decision connected to each expert report. This would be most practicable in contexts where government is required or expected to respond to advisory reports. Also, this kind of analysis requires a systematic strategy for coding the degree of correspondence between the expert report and the final policy document across a large number of cases. There are also other problems, such as whether the correspondence between expert preferences and final decisions actually reflects expert influence or rather the influence of other actors with similar preferences.

\section{The administrative underpinnings of expert influence}

The second suggestion for future research concerns the explanation of expert influence. As argued earlier, a crucial issue that has received insufficient attention is how the organisation of expert knowledge within government bureaucracies conditions expert influence. That is, how do features and dynamics of public administrations affect the ability of expert actors to shape policy decisions in line with their preferences?

To understand the administrative underpinnings of expert influence, two questions particularly deserve closer attention. First, several contributions suggest that the bureaucratic position of experts matters for the influence of expert knowledge (Haas, 1992; Babb, 2004; Chwieroth, 2010). But what explains the varying position of specialised experts in government bureaucracies? Comparative-historical studies have shown that the role of experts and expert knowledge in public bureaucracies differs considerably across countries and organisations, and have started to explore the sources of this variation (Weir and Skocpol, 1985; Fourcade, 2009). We have little systematic knowledge, however, about how the organisation of the bureaucracy matters for the access of experts to the administrative apparatus.

Organisational theory can be helpful in this regard, as it highlights several organisational factors that may condition the bureaucratic position of experts. One is the structural division of tasks within an organisation, which shapes the loyalties, preferences and communication patterns of civil servants (Egeberg, 1993; see also Smith, 2013). For instance, an organisation where tasks are divided according to process (for example, legal, economic processes) may be more susceptible to the formation of strong expert communities. Recruitment and staff policies can have the same effect: whether civil servants are recruited through central competitions testing general skills or through decentralised hiring emphasising position-relevant skills will affect how easy it is for specialised experts to enter the organisation (Peters, 2010; Christensen, 2015). Moreover, the existence of institutional venues for bureaucratic-academic exchange - for example, inquiry commissions where civil servants and academics interact - is likely to facilitate the access of expert knowledge to the bureaucracy (Weir and Skocpol, 1985).

Researchers, however, should also pay greater attention to how the position of experts in government bureaucracies is affected by changes in the societal, political and intellectual environment (Christensen, 2017). First, new societal challenges may 
affect the bureaucratic position of expert groups by giving rise to demands for new forms of expertise and casting doubt on whether the existing competences of the bureaucracy are still relevant. Second, economic crisis and other forms of crisis may have the same effect: by exposing the shortcomings of the knowledge underlying existing policies, it may delegitimise existing bureaucratic experts and set off a search for other forms of expert knowledge that can help resolve the crisis (Blyth, 2002; Campbell and Pedersen, 2014). Third, a change of government may affect the place of expert groups in the bureaucracy by bringing politicians to power who have other political goals and other opinions about what constitutes relevant expertise for achieving these goals. Finally, the administrative position of experts may be affected by changes within expert professions themselves. For instance, the development of new academic ideas or more sophisticated analysis tools can make the knowledge of an expert profession more attractive for decision-makers.

Understanding how administrative features condition expert influence also requires more research into a second and subsequent question: How does the administrative position of experts affect decision-making? More specifically, how does expertise shape the political-administrative relationship that lies at the centre of policy formulation? Weber's fundamental insight that specialised knowledge puts the bureaucrat in a position of power relative to the political master is often repeated (Weber, 1946:232). But the specific mechanisms of this relationship are seldom explored. One aspect is how the analytical competences of bureaucrats condition their ability to set the agenda and define policy problems and solutions vis-a-vis the political principal (for example, Baekgaard et al, 2018). Under which conditions does the often superior expertise of bureaucrats relative to politicians translate into agenda control and policy influence? A less considered aspect is how the professional norms of expert bureaucrats shape their behaviour vis-a-vis politicians, such as their willingness to advocate particular policies regardless of opposition from elected leaders. Studies suggest that these norms may vary depending on the educational background of officials. For instance, the strong professional identification of bureaucrats with economic training may lead them to take an activist approach to policy advice (Christensen, 2017; see also Markoff and Montecinos, 1993; Mandelkern, 2019).

These two questions reflect a process-based understanding of expert influence. While the first question is about explaining the access of experts to decision-makers (step $\mathrm{b}$ in the process of expert influence outlined earlier), the second question is about explaining expert attempts to promote their preferences, decision-maker responses to these attempts and the resulting degree of expert influence on decisions (steps c-e). Moreover, both questions aim at complex causality (that is, multiple factors interacting) and target the mechanisms accounting for particular outcomes. All this makes a process-tracing methodology particularly well suited to examining these questions. For instance, the organisational and environmental factors affecting the bureaucratic position of experts can be examined through comparative-historical studies that rely on a combination of co-variational analysis (that is, examining the effect of a certain factor by holding other factors constant across cases) and process-tracing (to uncover the mechanisms linking the position of experts to an explanatory factor) (Blatter and Haverland, 2012). Furthermore, the impact of expertise on political-administrative interactions can be examined in single-case or small-n studies that use interviews with politicians and bureaucrats to uncover the specific mechanisms underlying this relationship. 


\section{Conclusion}

The article has highlighted the problems associated with the currently fragmented state of research on expert knowledge in public policymaking. In order to advance systematic empirical research on the topic, scholars need to engage in genuine dialogue across literatures. The article has offered two suggestions about how to create common ground for future research: putting the influence of experts front and centre and examining more closely the administrative underpinnings of expert influence.

Certainly, one can challenge the basic premise of the article, namely that the fragmentation of research on expertise and policymaking constitutes a problem. Some would instead see this theoretical diversity as a strength: by illuminating the issue from a multitude of perspectives, scholars have generated a rich understanding of how expert knowledge shapes public policies. The multiplicity of concept and arguments about expertise and policymaking may simply reflect the specific interests and orientations of different sub-fields. While this argument is not without merit, there are reasons to be sceptical: first, the across-literature discussion has revealed significant theoretical weaknesses and barriers to empirical study that have not been seriously addressed within the respective literatures. This suggests that breaking down the silos and exposing each literature to outside criticism is important for advancing research. Second, the article has shown how the concepts and arguments proposed by different literatures shape our understanding of the policy role of expert knowledge, by focusing attention on a particular object of study and on particular explanatory factors. These concepts are therefore not neutral; they have specific implications for interpretation, of which researchers need to be aware.

One can also question whether a cross-disciplinary understanding of expertise and policymaking is possible and will be used by scholars. The literatures discussed in the article rest on partly different ontologies, and these differences are especially pronounced if you compare rationalist work on evidence-based policymaking and the STS literature. Differing fundamental assumptions about how the social world works may frustrate attempts at establishing shared understandings.Yet, the differences should not be overstated: there is potentially much common ground between most of the literatures. There are also excellent examples of research that borrows concepts from other sub-fields, such as the application of theory on expert professions to the study of international relations and organisations (Chwieroth, 2010). In other words, taking a cross-cutting view can open up fruitful avenues for research on an increasingly important aspect of public policymaking.

\section{Funding}

This research was supported by a project grant from the Research Council of Norway (project number 254767).

\section{Acknowledgements}

I am grateful to my colleagues at Leiden University and the University of Oslo, and to participants at the SOG Conference at the University of Potsdam, June 20-21, 2018, for comments on earlier versions of the article. I also thank the editor and two anonymous referees for their comments and suggestions. 
Postal address: Institute of Public Administration, P.O. Box 13228, 2501 EE The Hague, Netherlands

\section{Notes}

${ }^{1}$ For instance, the related and partly overlapping literature on policy learning is left out, given that expert knowledge is only one (and arguably not the most central) element in accounts of learning (for reviews, see Bennett and Howlett, 1992 and Dunlop and Radaelli, 2013). The article also leaves out literatures on expert knowledge where there has been less activity recently, such as discussions of expertise in the implementation literature.

2 This approach has recently been particularly prominent in studies of EU politics and policymaking.

${ }^{3}$ STS scholarship has also paid extensive attention to the issues of what expertise is and who has expertise, discussions that are not taken up in this article.

${ }^{4}$ The epistemic community concept is also frequently applied outside international relations, particularly in studies of government/politics and public administration (Dunlop, 2013).

\section{Conflict of interest}

The author declares that there is no conflict of interest.

\section{References}

Abbott, A. (1988) The System of Professions: An Essay on the Division of Expert Labor, Chicago, IL: University of Chicago Press.

Adler, E. and Haas, P.M. (1992) Conclusion: epistemic communities, world order, and the creation of a reflective research program, International Organization, 46(1): 367-90. doi: 10.1017/S0020818300001533

Babb, S.L. (2004) Managing Mexico: Economists from Nationalism to Neoliberalism, Princeton, NJ: Princeton University Press.

Baekgaard, M., Mortensen, P.B. and Seeberg, H.B. (2018) The bureaucracy and the policy agenda, Journal of Public Administration Research and Theory, 28(2): 239-53. doi: 10.1093/jopart/mux045

Béland, D. and Cox, R.H. (eds) (2010) Ideas and Politics in Social Science Research, Oxford: Oxford University Press.

Bennett, C.J. and Howlett, M. (1992) The lessons of learning: reconciling theories of policy learning and policy change, Policy Sciences, 25: 275-94. doi: 10.1007/ BF00138786

Blatter, J. and Haverland, M. (2012) Designing Case Studies: Explanatory Approaches in Small-N Research, Basingstoke: Palgrave Macmillan.

Blyth, M. (2002) Great Transformations: Economic Ideas and Institutional Change in the Twentieth Century, Cambridge: Cambridge University Press.

Boswell, C. (2008) The political functions of expert knowledge, Journal of European Public Policy, 15(4): 471-88. doi: 10.1080/13501760801996634

Burstein, P. and Linton, A. (2002) The impact of political parties, interest groups, and social movement organizations on public policy: some recent evidence and theoretical concerns, Social Forces, 81(2): 380-408. doi: 10.1353/sof.2003.0004 
Cairney, P., Oliver, K. and Wellstead,A. (2016) To bridge the divide between evidence and policy: reduce ambiguity as much as uncertainty, Public Administration Review, 76(3): 399-402. doi: 10.1111/puar.12555

Campbell,J.L. (2002) Ideas, politics, and public policy, Annual Review of Sociology, 28: 21-38 doi: 10.1146/annurev.soc.28.110601.141111

Campbell,J.L. and Pedersen, O.K. (2014) The National Origins of Policy Ideas, Princeton, NJ: Princeton University Press.

Chalmers, A.W. (2011) Interests, influence and information: comparing the influence of interest groups in the European Union, Journal of European Integration, 33(4): 471-86. doi: 10.1080/07036337.2011.579751

Christensen,J. (2015) Recruitment and expertise in the European Commission, West European Politics, 38(3): 649-78. doi: 10.1080/01402382.2014.982353

Christensen, J. (2017) The Power of Economists within the State, Stanford, CA: Stanford University Press.

Christensen,J.G. (2018) Bureaucrats as evidence brokers, Journal of Public Administration Research and Theory, 28(1): 160-3.

Chwieroth, J.M. (2010) Capital Ideas:The IMF and the Rise of Financial Liberalization, Princeton, NJ: Princeton University Press.

Cox, R.H. and Béland, D. (2013) Valence, policy ideas, and the rise of sustainability, Governance, 26(2): 307-28. doi: 10.1111/gove.12003

Cross, M.K. Davis (2013) Rethinking epistemic communities twenty years later, Review of International Studies, 39: 137-60. doi: 10.1017/S0260210512000034

Davies, H., Nutley, S. and Smith, P. (2000) Introducing evidence-based policy and practice in public services, in H. Davies, S. Nutley and P. Smith (eds) What Works? Evidence-based Policy and Practice in Public Services, Bristol: Bristol University Press, pp. 1-11.

Daviter, F. (2015) The political use of knowledge in the policy process, Policy Sciences, 48: 491-505 doi: 10.1007/s11077-015-9232-y

DiMaggio, P.J. and Powell, W.W. (1983) The iron cage revisited: institutional isomorphism and collective rationality in organizational fields, American Sociological Review, 48(2): 147-60. doi: 10.2307/2095101

Dunlop, C. (2013) Epistemic communities, in E. Araral Jr., S. Fritzen, M. Howlett, M. Ramesh and X.Wu (eds) Routledge Handbook of Public Policy, London: Routledge, pp. 229-43.

Dunlop, C. and Radaelli, C. (2013) Systematising policy learning: from monolith to dimensions, Political Studies, 61: 599-619. doi:10.1111/j.1467-9248.2012.00982.x

Dür,A. (2008) Measuring interest group influence in the EU: a note on methodology, European Union Politics, 9(4): 559-76.

Egeberg, M. (1993) How bureaucratic structure matters: an organizational perspective, in B.G. Peters and J. Pierre (eds) Handbook of Public Administration, London: Sage.

Fourcade, M. (2006) The construction of a global profession, American Journal of Sociology, 112(1): 145-94. doi: 10.1086/502693

Fourcade, M. (2009) Economists and Societies, Princeton, NJ:Princeton University Press.

Grundmann, R. (2017) The problem of expertise in knowledge societies, Minerva, 55: 25-48. doi: 10.1007/s11024-016-9308-7

Haas, P.M. (1992) Introduction: epistemic communities and international policy coordination, International Organization, 46(1): 1-35. doi: 10.1017/ S0020818300001442 
Hall, P.A. (1989) The Political Power of Economic Ideas: Keynesianism across Nations, Princeton, NJ: Princeton University Press.

Hall, P.A. (1993) Policy paradigms, social learning, and the state: the case of economic policymaking in Britain, Comparative Politics, 25(3): 275-96. doi: 10.2307/422246

Head, B.W. (2015) Toward more evidence-informed policy-making, Public Administration Review, 76(3): 472-84. doi: 10.1111/puar.12475

Hirschman, D. and Berman, E.P. (2014) Do economists make policies? On the political effects of economics, Socio-Economic Review, 12(4): 779-811. doi: 10.1093/ ser/mwu017

Jasanoff, S. (2005a) Judgment under siege: the three-body problem of expert legitimacy, in S. Maasen and P. Weingart (eds) Democratization of Expertise?, Dordrecht: Springer, pp. 209-24.

Jasanoff, S. (2005b) Designs on Nature: Science and Democracy in Europe and the United States, Princeton, NJ: Princeton University Press.

Jennings, E.T. and Hall,J.L. (2012) Evidence-based practice and the use of information in state agency decision-making, Journal of Public Administration Research and Theory, 22: 245-66. doi: 10.1093/jopart/mur040

Landry, R., Lamari, M. and Amara, N. (2003) The extent and determinants of the utilization of university research in government agencies, Public Administration Review, 63(2): 192-205. doi: 10.1111/1540-6210.00279

Larson, M.S. (1979) The Rise of Professionalism: A Sociological Analysis, Berkeley, CA: University of California Press.

Mandelkern, R. (2019) Neoliberal ideas of government and the political empowerment of economists in advanced nation-states: the case of Israel, Socio-Economic Review, (early view)

March, J.G. (1955) An introduction to the theory and measurement of influence, American Political Science Review, 49(2): 431-51. doi: 10.2307/1951813

Markoff, J. and Montecinos, V. (1993) The ubiquitous rise of economists, Journal of Public Policy, 13(1): 37-68. doi: 10.1017/S0143814X00000933

Newman, J. (2017) Deconstructing the debate over evidence-based policy, Critical Policy Studies, 11(2): 211-26. doi: 10.1080/19460171.2016.1224724

Nichols, T. (2017) The Death of Expertise: The Campaign against Established Knowledge and Why It Matters, New York: Oxford University Press.

Oh, C.H. and Rich, R.F. (1996) Explaining use of information in public policymaking, Knowledge and Policy, 9(1): 3-35. doi: 10.1007/BF02832231

Oliver, K., Innvar, S., Lorenc, T., Woodman, J. and Thomas, J. (2014) A systematic review of barriers to and facilitators of the use of evidence by policymakers, $B M C$ Health Services Research, 14(2). doi: 10.1186/1472-6963-14-2

Parkhurst, J. (2017) The Politics of Evidence: From Evidence-Based Policy to the Good Governance of Evidence, London: Routledge.

Peters, B.G. (2010) The Politics of Bureaucracy, New York: Routledge.

Pielke, R.A. Jr (2007) The Honest Broker: Making Sense of Science in Policy and Politics, Cambridge: Cambridge University Press.

Radaelli, C. (1995) The role of knowledge in the policy process, Journal of European Public Policy, 2(2): 159-83. doi: 10.1080/13501769508406981

Radaelli, C. (1999) The public policy of the European Union: whither politics of expertise?, Journal of European Public Policy, 6(5): 757-74. doi: $10.1080 / 135017699343360$ 
Rimkute, D. and Haverland, M. (2015) How does the European Commission use scientific expertise?, Comparative European Politics, 13: 430-49.

Sabatier, P.A. (1987) Knowledge, policy-oriented learning, and policy change - an advocacy coalition framework, Knowledge: Creation, Diffusion and Utilization, 8(4): 649-92.

Schrefler, L. (2010) The usage of scientific knowledge by independent regulatory agencies, Governance, 23(2): 309-30. doi: 10.1111/j.1468-0491.2010.01481.x

Smith, K. (2013) Institutional filters: the translation and re-circulation of ideas about health inequalities within policy, Policy \& Politics, 41(1): 81-100.

Verdun, A. (1999) The role of the Delors Committee in the creation of EMU: an epistemic community?, Journal of European Public Policy, 6(2): 308-28. doi: 10.1080/135017699343739

Weber, M. (1946) Bureaucracy, in C. Wright Mills and H.H. Gerth (eds) From Max Weber: Essays in Sociology, New York: Oxford University Press, pp. 196-244.

Weible, C.M. (2008) Expert-based information and policy subsystems: a review and synthesis, Policy Studies Journal,36(4):615-35. doi:10.1111/j.1541-0072.2008.00287.x

Weingart, P. (1999) Scientific expertise and political accountability: paradoxes of science in politics, Science and Public Policy, 26(3):151-61. doi:10.3152/147154399781782437

Weir, M. and Skocpol, T. (1985) State structures and the possibilities for 'Keynesian' responses to the Great Depression in Sweden, Britain, and the United States, in P.B. Evans, D. Rueschemeyer and T. Skocpol (eds) Bringing the State Back In, New York: Cambridge University Press, pp. 107-63.

Weiss, C.H. (1979) The many meanings of research utilization, Public Administration Review, 39(5): 426-31. doi: 10.2307/3109916

Wilensky, H.L. (1964) The professionalization of everyone?, American Journal of Sociology, 70(2): 137-58. doi: 10.1086/223790 